\title{
TRANSLATION. \\ A CASE STUDY IN BYZANTINE SCIENCE
}

\author{
Alain Touwaide \\ Institute for the Preservation of Medical Traditions \\ and Smithsonian Institution \\ touwaida@si.edu
}

In a traditional historical narrative, the very concept of translation does not apply much to Byzantium. It rather concerns the neighboring worlds of the Empire, which absorbed and further reworked and circulated the Byzantine body of knowledge. This is particularly the case of medicine. Byzantium received the legacy of Antiquity, the Corpus Hippocraticum, the immense oeuvre of Galen, De materia medica by Dioscorides and many other works of equal or minor importance and extension. It perpetuated their tradition, which it also remodeled and reorganized when necessary. From its major centers of learning it circulated this legacy and made it possible to develop a new local knowledge, born from the translation of the ancient heritage.

Characteristically enough, this process of transmission of medicine from Byzantium to its surrounding worlds and cultures has often been attributed to learned circles of translators operating in the context of well defined cultural structures. Besides gothic Ravenna in the West, which seems to have emulated the model of the Alexandrian school of medicine and generated Latin translations of a set of Hippocratic and Galenic treatises used as text books in Alexandria, we could mention here the cases of Gondishapur and Baghdad in the East. In the odyssey of Greek medicine from the Greek, viz. Byzantine world to the Arabic one, the transfer proceeded by phases, passing through Syriac. The translation activity into Syriac was located in the university of Gondishapur, whereas the translation into Arabic, be it from Syriac or later on directly from Greek (sometimes in repeated translations), was situated in the Bayt al-Hikmat (House of Wisdom), considered as an Academy or a translation agency. There, a main translator - Hunayn ibn Ishaq (808-873) - worked first alone and then with a group of collaborators. He could count on the support of wealthy mecenates who funded his work and were directly responsible for the introduction of Greek medicine into the Arabic world. 
Without entering into the details of current revisions of such historical reconstructions (such as the relatively recent understanding that information in the sources about the Bayt al-Hikmat has been misunderstood in previous historiography, as the Bayt al-Hikmat was probably neither an Academy nor a translation agency, but more simply an informal group of individuals), I will only stress the rigidity of the interpretative schemes beyond such historical narratives. These narratives tend indeed to locate the translation activity in definite spaces (major cities) and precise structures (schools, academies or agencies), to limit its production to the activity of determined groups operating in these spaces and structures, and to credit a reduced number of individuals with the merit of having rendered a substantial textual body into the translated language, most often thanks to the financial support of an élite acting as patrons.

A systematic census of primary sources and their close scrutiny -actually the compilation of a World Census of Greek Medical Manuscripts (Touwaide, I99I, 1992, 2008, 2009) — is bringing new keys for the understanding of the translation activity in the Eastern Mediterranean World during the time period of the Byzantine Empire and leads the interpretation of translation activity in a very different direction. It suggests indeed that translation is not necessarily a process guided from an upper class of wealthy patrons and carried out by leading intellectuals working in learned centers, but may have come from the world of practitioners of different linguistic origins (that is, from the source and the target languages), working in collaboration or at least frequenting each other and generating translations for commodity reasons, most probably without any pre-established program or outside any cultural vision. Instead, such translation activity might have arisen from necessity among populations of different ethnic origins living in contact with each other.

Specifically, the Census of Greek Medical Manuscripts has brought to the attention a significant number of codices whose texts are explicitly presented in their titles as translations from Arabic or can be identified as such because of their lexicon made, among others, of Arabic terms not translated but simply transliterated from the Arabic into the Greek alphabet (Touwaide, 2002). This collection of texts and manuscripts indicates that the process of translation was not unidirectional from a central culture to those at its periphery as the traditional narrative has always posited, but could very well include a process of reverse diffusion from the world that previously benefitted from translation to the one that provided the material to be translated.

One text is particularly significant to illustrate both the process of reverse diffusion and the possible unprogrammed nature of translation activity. It is the Greek version of the Arabic Zäd al-musäfir wa qut al-hadir (Provisions for the 
traveler and nourishment for the sedentary) originally written by the Arabic physician Abū Ja’fār Ahmad b.Abī Khālid ibn al Jazzār († 979/980 - ıoıo A.D. ca.). Best known in Greek under the abbreviated title Efodia (instead of Efodia tôn apodêmountôn, that is, literally Supplies for travelers) this work is attested by an exceptionally high number of manuscripts (more than three dozens). Authorship of the translation is attributed to a certain Kônstantinos not better known, although it is qualified in some manuscripts as Rêginos (that is, of Reggio) and in some others as Memfitês (that is, of Memphis). This Kônstantinos has been identified - but without convincing evidence- as Constantine the African (d. after I087), particularly because the African translated the same Arabic treatise into Latin as the Viaticum peregrinantium.

Contrary to its text, which is not well known and has not been studied until recently, a manuscript of the Efodia-actually the codex Vaticanus graecus 300-has been scrutinized in great detail, particularly because one of its hands is most probably identical to one of the so-called Skylitzes of Madrid, that is, the codex of Madrid, Biblioteca Nacional, Vitr. 26-2 containing the text of the Synopsis of [Byzantine] History (Sunopsis istorion) for the period 8II-IO57 by the Byzantine historian Ioannês Skylitzês and most famous for its lavish set of illustrations representing various scenes of the historical facts narrated in the text. This manuscript has made the object of intense paleographical scrutiny and has been attributed to different milieux in Sicily and in the south of the Italian peninsula, all of them of higher education. On this basis, the translation of the text it bears has been linked with such intellectual circles (Touwaide, 2008b).

The examination of the translation-particularly the comparison of the original Arabic text (Bos, 1997) and its Greek translation from manuscript Vaticanus graecus 300-reveals several translation techniques and patterns of which I will mention some examples organized by major categories of processes:

I. Reproduction of technical terms and Arabic plant names

f. 197 recto $=$ p. 298 , 1. I3: zekzeneie

f. 197 recto $=$ p. 298 , 1. I4: moukol

2. Double names of plants and materia medica

f. 180 verso $=$ p. $267,1.25:$...sagapênon called sikipinetz and yellow bdellion, which is moukol azrak...

f. 183 recto $=$ p. $27 \mathrm{I}$, 1. I2: ...the African snail called ouetala...

f. 183 recto $=$ p. $272,1.7:$...the zarour peach... 
3. Equivalence of the Muslim and Western calendars

f. 202 recto $=$ p. 305 , 1. I4: ...during the month of nisen, that is, in april...

4. Explanations of the text (explanatory additions are in bold)

f. 187 verso $=$ p. $280,1.8$ : ...If the edema is cold and thick - that is, if the cause [of the edema] is cold and thick...

f. 194 recto = p. 293, 11. I-3: ...it evacuates the epiploos and the fetus (with epiploos I mean the membrane that recovers the fetus) (often, this membrane remains in the womb of the mother and provokes a harsh pain)...

5. Minor additions

f. 204 recto $=$ p. $308,1.8:$...this medicine fits well for wealthy people...

\section{Addition of ingredients}

f. 183 recto $=$ p. 272 , 1. Io: ... take ... roses and also gasel and souberon of sonobar...

7. Adaptation (religious) of the text

Efodia (f. 165 recto)

...reproduction requires two animals - a male and a female, God - may He be blessed (Greek: $o$ megas theios) - has created organs that fit...

Ibn al-Jazzar (p. 240)

...but since procreation requires two animals, namely, male and female, $\mathrm{He}$ created - may He be blessed and exalted - organs that fit...

8. Introduction of geographical data (additions are in bold)

f. 180 verso $=$ p. $267,1.23$ : ...aloe from Socotra-it is the name of a country...

f. I8I recto - p. 268, 1. 26: ...alum from Yemen (it is the name of a country) (where there is a city called mefirke) (its name in Greek is sideropolis) (it is Io days away from Babylon) (that is, Baghdad) (where John Damascenus was born)...

All these facts suggest not only a translation made in a bilingual milieu (as the Arabic additions to the translation for example seem to indicate), but also several layers of accretions (as the specifications in cascade about the origin of the alum from Yemen makes clear).

At this point, it would seem that a first-hand version of the text was possibly more Arabo-Greek than the one attested by the Greek manuscripts and that such version was reworked by successive generations of readers who added elements of clarification. This additions were most probably added in the margins or between 
the lines of a manuscript and were further integrated into the main text according to a well-known process.

The possible redaction of the translation by later hands may have included scholarly contributors as some peculiarities of the Greek text when compared to its Arabic equivalent may suggest:

I. Addition with references to Greek classical texts (additions are in bold)

f. 192 verso $=$ p. 290 : Chapter on the treatment of difficult parts (which Galen has treated in his works) (in the treatise on substitution products)...

f. 196 recto $=$ p. 296 , 1. 15: ...According to Hippocrates, at the beginning of the first section...

2. Additions with references to other Greek medical treatises

f. 196 verso = p. 297: ...you need to know the signs [of this disease] which you will find in the treatise entitled Healthy and pathological humors...

f. 197 recto $=$ p. 298 , 1. I4: ... and other similar (you will find these formulae in another work where they are explained one by one)...

As all these examples indicate, the translation was probably not prepared in a learned milieu, but more probably among practitioners who may have been bilingual unless they were Greek and Arabic speakers working together, using some sort of common language and understanding each other. The location of the translation in Sicily makes such interpretation highly plausible, given the diversity of the population in the island at the probable time of the translation.

If our analysis is correct, this translation highlights two interesting phenomena that have not necessarily been noticed in previous scholarly literature. Firstly, a translation made in the field, possibly by practitioners as an operational instrument was further assimilated and subsumed in higher medical literature and even arrived among a higher education milieu in an ascendent movement within society that is contrary to the descendent circulation often attributed to texts by scholars, going from higher groups of society to practitioners in the case of medicine. Secondly, wherever this translation was made in Sicilian society, it further circulated from the island to Constantinople where it had quite a wide diffusion. Again, this movement of circulation of a text and the science and ideas that it contains-going from the periphery to the center-is contrary to the movement of diffusion traditionally attributed to culture, from the center to the periphery. If a third major conclusion differing from generally accepted assumptions were needed, one could add that the text had quite a diffusion during the Renaissance, something that may contradict the idea of a Renaissance anti-Arabism. 
BIBLIOGRAPHY

Bos, G., 1997: Ibn al-Jazzar on Sexual Diseases: A critical edition, English translation and introduction of Zad al-musafir wa-qut al-hadir. Provisions for the Traveler and Nourishment for the Sedentary. Book 6, The original Arabic text, with an English translation, introduction and commentary, London.

Touwaide, A., I99I: "The Corpus of Greek Medical Manuscripts: A Computerized Inventory and Catalogue", Primary Sources and Original Works, I, pp. 75-92.

— I 1992: "Pour un Corpus des manuscrits médicaux gecs", in A. Garzya (ed.), Tradizione e ecdotica dei testi medici tardo-antichi e bizantini. Atti del Convegno internazionale, Anacapri, 29-3I ottobre 199o, Naples, pp. 356-366.

—, 2002: "Arabic Medicine in Greek Translation. A Preliminary Report", Journal of the International Society for the History of Islamic Medicine, I, pp. 45-53.

—, 2008: "Greek Medical Manuscripts. Toward a New Catalogue", Byzantinische Zeitschrift, I0I, pp. 199-208.

— , 2008b: "Medicina Bizantina e Araba alla Corte di Palermo", in N. G. De Santo and G. Bellinghieri (eds.). Medicina, Scienza e Politica al Tempo di Federico II. Conferenza Internazionale, Castello Utveggio, Palermo, 4-5 ottobre 2007, Naples, pp. 39-55.

— 2009: "Byzantine Medical Manuscripts: Towards a New Catalogue with a Specimen for an Annotated Checklist of Manuscripts Based on an Index of Diels' Catalogue", Byzantion, 79, pp. 453-595. 